\title{
Application of Wavelet and EEMD Joint Denoising in Nonlinear Ultrasonic Testing of Concrete
}

\author{
Zhichao Nie, ${ }^{1}$ Kui Wang $\mathbb{D}^{1,2}$ and Mingjie Zhao ${ }^{1,2}$ \\ ${ }^{1}$ Key Laboratory of Hydraulic and Waterway Engineering of Ministry of Education, Chongqing Jiaotong University, \\ Chongqing 400074, China \\ ${ }^{2}$ Engineering Research Center of Diagnosis Technology and Instruments of Hydro-Construction, Chongqing Jiaotong University, \\ Chongqing 400074, China \\ Correspondence should be addressed to Kui Wang; anhuiwk@163.com
}

Received 15 September 2017; Revised 20 March 2018; Accepted 16 April 2018; Published 16 May 2018

Academic Editor: Santiago Garcia-Granda

Copyright (c) 2018 Zhichao Nie et al. This is an open access article distributed under the Creative Commons Attribution License, which permits unrestricted use, distribution, and reproduction in any medium, provided the original work is properly cited.

\begin{abstract}
The health state of concrete is deteriorating during its service. Nonlinear ultrasonic detection based on the amplitude of the fundamental and the second harmonic is considered to be a powerful tool for the discovery of the microcrack in concrete. However, the research on processing the nonlinear ultrasonic signal is still insufficient. In order to highlight the real frequency domain components in the nonlinear ultrasonic signal, wavelet and ensemble empirical mode decomposition (EEMD) were joined to denoise the numerical and measured signal. The optimal wavelet base and the decomposition level were determined by the signal-to-noise ratios (SNRs). Then, the wavelet threshold denoising signal was decomposed by EEMD, omitting the highfrequency components and ultimately achieving the desired denoising effect. The denoising result of the test signals demonstrates that this method is effective in denoising the details of the ultrasonic signal and improving the reliability and adaptability of the nonlinear ultrasonic testing. In this experiment, the concrete with the microcrack was tested by linear and nonlinear ultrasonic methods. Based on the variation regularity of the nonlinear ultrasonic coefficient $\beta$ and velocity $v$, we can conclude that the nonlinear ultrasonic parameter $\beta$ is more sensitive to the microcrack in concrete than the traditional wave velocity $v$. The nonlinear ultrasonic testing can be an important supplement to the current nondestructive testing technique of the concrete.
\end{abstract}

\section{Introduction}

Nonlinear ultrasonic technique has been considered as a promising method for detecting the microdamage of materials [1]. Lissenden's research shows that when singlefrequency ultrasonic waves pass through the damaged area of the medium, the tensile-compression asymmetry, shearnormal coupling, and deformation-induced compression asymmetry are the reasons for the generation of high-order harmonics [2]. At present, the research on the nonlinear ultrasonic technique is mainly focused on the following aspects: (1) Experimental study on dislocation slip damage for metal material (microscale) [3, 4]. (2) Experimental and numerical simulation study on closed crack damage for metal or nonmetallic materials (mesoscale) [5-7]. (3) Exploration of the generation and propagation mechanism of nonlinear ultrasound [8-10]. However, the amplitude of higher order harmonic in signals tends to be smaller and differ by one to two orders from the fundamental. Therefore, it is difficult to accurately measure the amplitude of the high-order harmonic in the experiment, and an effective signal processing method is needed.

Wavelet-based denoising and compression have been widely used in engineering, biology, and so on. Staszewski compared the wavelet compression effects of the periodic, continuous nonstationary and transient nonstationary vibration signals, providing data compression selecting basis for different types of signals [11]. In addition, the wavelet transform also has the ability to recognize the damage of the material or structure. Using orthogonal wavelet transform and setting the appropriate threshold value, the reflected wave features caused by defect can be effectively displayed [12]. Another important application of the wavelet-based technique is signal denoising. The combined denoising method based on wavelet 
entropy was proposed by Hou and Gui, which processes the high-frequency wavelet decomposition coefficients with wavelet entropy thresholds under different scales [13]. Cunha et al. determined the wavelet functions based on the SNR computed from the wavelet coefficients, and the wavelet decomposition level was chosen according to the energy spectral density principle [14]. The proposed method provides a new thought and approach for the selection of wavelet basis and decomposition layer in wavelet denoising.

Unlike the wavelet transform, the empirical mode decomposition (EMD) can be decomposed adaptively according to the trend of the signals. Wu and Huang added the Gaussian white noise to the original signal to supplement the missing frequency components and obtained desired decomposition results [15]. A major application of EEMD is to extract intrinsic mode functions (IMFs) from the vibration signals to identify the mechanical faults. Žvokelj et al. proposed the EEMD-based multiscale ICA (EEMDMSICA) method. The rotating machinery vibration signals are analyzed by this method, and the bearing fault can be detected [16]. In addition, Ridder et al. compared the SNR acquired by EEMD, wavelet, and FIR denoising and considered the wavelet denoising method is the best [17]. Wei et al. denoised the IMF components using $3 \sigma$ criteria, singular value decomposition, and SG filtering. The superiority of this method was verified by processing the simulated and experimental data [18].

In order to accurately extract the amplitude of the fundamental and the second harmonic, this paper uses wavelet and EEMD joint method to denoise the numerical signal containing higher order harmonics, which tend to be more effective than a single step denoising. Then, the nonlinear ultrasonic experiment was carried out. And the wavelet and EEMD joint denoising method was applied to the experimental signal, gaining the correlation between the cracked angle and nonlinear coefficient $\beta$.

\section{Denoising Method}

2.1. Wavelet Threshold Denoising Theory. Wavelet theory originated in the late 19th century and has been widely applied in various fields. Wavelet threshold denoising is one of the important applications of the wavelet theory proposed by Donoho and Johnstone. The main idea is comparing each level of wavelet coefficients with the selected threshold. When the wavelet coefficient is greater than the selected threshold, it is completely preserved or shrunk. These wavelet coefficients are considered as the original components of the signal. Otherwise, the wavelet coefficients are zero setting. Then, the detail and approximation coefficients are reconstructed, and the wavelet threshold denoising is accomplished [19].

The traditional hard and soft threshold functions are shown in the following equations:

$$
\begin{aligned}
& \omega_{j, k}^{\prime}= \begin{cases}\omega_{j, k}, & \left|\omega_{j, k}\right| \geq \lambda \\
0, & \left|\omega_{j, k}\right|<\lambda,\end{cases} \\
& \omega_{j, k}^{\prime}= \begin{cases}\operatorname{sgn}\left(\omega_{j, k}\right)\left(\left|\omega_{j, k}\right|-\lambda\right), & \left|\omega_{j, k}\right| \geq \lambda \\
0, & \left|\omega_{j, k}\right|<\lambda,\end{cases}
\end{aligned}
$$

where $\omega_{j, k}$ is the detail coefficient, $\omega_{j, k}^{\prime}$ is the detail coefficient after denoising, $\lambda$ is the wavelet threshold, and $\operatorname{sgn}()$ is the symbolic function. According to (1) and (2), there are smoothness and continuity problems when denoising by the hard threshold function. When using the soft threshold function, it is very likely to lose important information in the original signal. In order to preserve the frequency domain characteristics of the ultrasonic signal as much as possible, this paper uses the hard threshold method. If the wavelet coefficients are greater than the selected threshold, keep them intact, otherwise 0 . In addition, the smoothness problem caused by the hard threshold method will be solved in the next step of EEMD.

The threshold selection rule is based on Stein's unbiased risk estimation:

$$
\lambda=\sigma_{\mathrm{n}} \sqrt{w_{\mathrm{b}}}
$$

where $\sigma_{\mathrm{n}}$ is the standard deviation of the noise signal and $w_{\mathrm{b}}$ is the risk function.

The unbiased risk threshold method needs to find the wavelet coefficient $c_{i}$ corresponding to the minimum risk value, and then the threshold value $\lambda$ is calculated according to it. Although the thresholds determined by this way are conservative and may result in incomplete noise removal, it is easier to separate useful weak components from noise when the high-frequency bands are confusing with noise.

Nonlinear ultrasonic testing requires using highfrequency information of the signal. However, the highfrequency band of the signal is more susceptible to noise pollution than low-frequency components. In view of the characteristics of the nonlinear ultrasonic experimental signal, it is appropriate to determine the threshold value by Stein's unbiased risk estimation to eliminate the noise in the high-frequency coefficients.

2.2. EEMD Denoising Method. In order to overcome the illusive components and mode mixing problems existing in EMD, additive Gaussian white noise is added to the original signal to supplement the missing frequency scale of the signal. The specific EEMD decomposition process is as follows [20]:

(1) Adding the Gaussian white noise $n(t)$ to the original signal $s(t)$ and obtaining a new signal $S(t)$ :

$$
S(t)=s(t)+n(t)
$$

(2) The signal $S(t)$ is decomposed by EMD to obtain the intrinsic modal function (IMF) $C_{1, j}(t)$ :

$$
S(t)=\sum_{j=1}^{n} C_{1, j}(t)+r_{1, n}(t) .
$$

(3) Adding the Gaussian white noise to the original signal $s(t)$ again and repeating the above steps: 


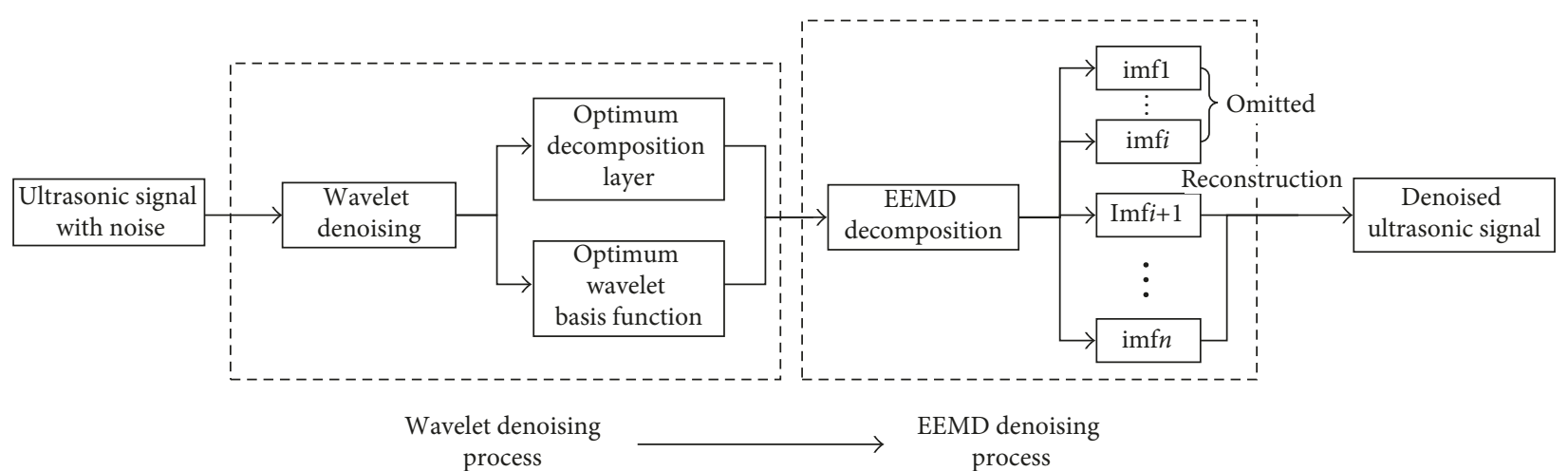

Figure 1: Wavelet and EEMD joint denoising method.

$$
S_{i}(t)=\sum_{j=1}^{n} C_{i, j}(t)+r_{i, n}(i \geq 2) .
$$

(4) Due to the entire frequency spectrum of the Gaussian white noise is zero, the time-frequency effect after adding the noise signal can be neglected. Average the superimposed intrinsic modal function:

$$
S_{n}(t)=\frac{1}{N} \sum_{i=1}^{N} C_{i, n}(t) .
$$

The noise signal can be decomposed from high frequency to low frequency adaptively by the EEMD method. By ignoring the high-order IMFs and reconstructing the remaining IMFs, the denoising signals are obtained.

2.3. Wavelet and EEMD Joint Denoising Method. The ultrasonic noise mainly comes from the ultrasonic machine, environment, and crystal scattering of materials, which is usually distributed in the high-frequency field of the received signal. Figure 1 is a flow chart of the denoising method. The appropriate wavelet base and the decomposition layer are selected to denoise the noise signal. Then, the signal is decomposed by EEMD. Because the noise is mainly distributed in the high-frequency range, the high-frequency components imf1 imfi are discarded and the remaining components are reconstructed [21].

\section{Numerical Signal Denoising}

3.1. Numerical Signals of Nonlinear Ultrasonic. According to the fundamentals of the finite amplitude method, the nonlinear ultrasonic signal can be simulated by two superimposed signals:

$$
y=100 \cos \left(2 \pi f_{1} * t\right)+10 \cos \left(2 \pi f_{2} * t\right) .
$$

The signal contains two parts: the center frequency is $50 \mathrm{kHz}$ and the second harmonic is $100 \mathrm{kHz}$. Besides, the sampling frequency is $2000 \mathrm{~Hz}$. Using the fast Fourier transform (FFT) to compute the numerical signal, the amplitude of the fundamental and the second harmonic are $9408 \mathrm{mV}$ and $1633 \mathrm{mV}$, respectively. Calculated by (8), the nonlinear coefficient $\beta_{0}$ is about $1.845 * 10^{-5}$ (Figure 2). Adding the Gaussian white noise to the numerical signal, according to the frequency domain curve of the noise signal, the amplitude of the fundamental and the second harmonic is $9293 \mathrm{mV}$ and $2187 \mathrm{mV}$, respectively. The calculated nonlinear parameter $\beta$ is about $2.532 * 10^{-5}$ (Figure 3).

Compared with Figures 2 and 3, it can be found that the smoothness of the time-domain curve is significantly decreasing after adding the Gaussian white noise. However, there are obvious features of burrs in the time-domain curve. In addition, the amplitude of the second harmonic is greatly increased, which leads to the increase of the nonlinear ultrasonic parameter $\beta$.

Table 1 shows the characteristic indicators of the numerical signal after noise reduction. From the data in Table 1, it can be seen that the characteristic indicators of the frequency domain have changed greatly compared with the numerical signals before adding the noise, and the error rate of the nonlinear coefficient $\beta$ is even $37.26 \%$. Therefore, it is necessary to find a more effective method to reduce the noise pollution of the signal for the sake of extracting more accurate nonlinear parameter $\beta$.

3.2. Wavelet Threshold Denoising. The effect of the wavelet threshold denoising depends largely on the selection of the wavelet basis and the decomposition level. In this paper, three kinds of wavelet families ( $\mathrm{symN}, \mathrm{dbN}$, and coifN) are used to denoise the signal with different decomposition levels. The corresponding SNR obtained by denoising with different wavelet basis functions and decomposition levels are shown in Figure 4. The distribution of the root-meansquare error (RMSE) is exactly the same as that of the SNR and is not described here.

The line chart shown in Figure 4 shows that the denoising effect is best when the three-level decomposition is performed on the wavelet decomposition. While the effect of the wavelet threshold denoising by two-level decomposition is not obvious, most of the noise is not filtered. For the wavelet denoising of four-layer decomposition, because the wavelet coefficients of each level are filtered, there occurs a phenomenon of excessive denoising. In addition, the effect of Coif wavelet family denoising on the ultrasonic signal is unsatisfactory, while the denoising effect of Db and Sym wavelet family is better. Specifically, for the Db and the Sym wavelet families, the denoising effect is superior and their 


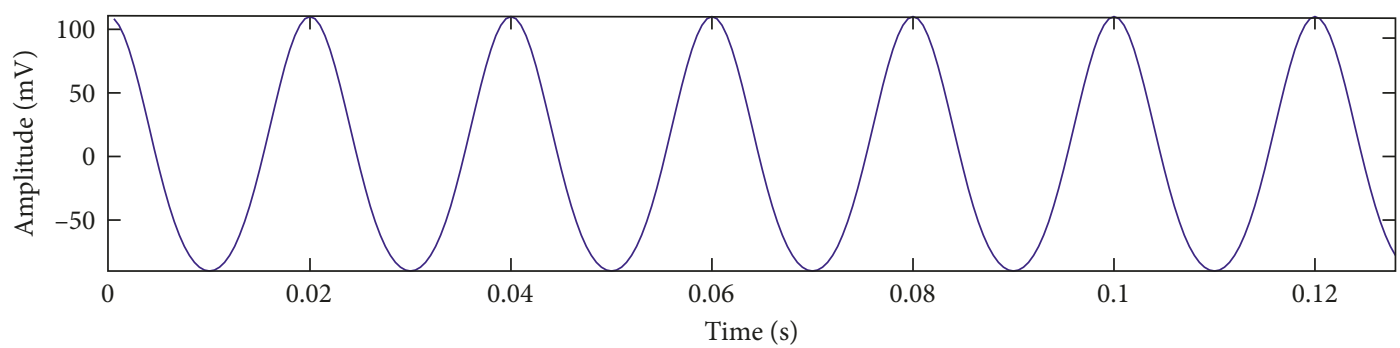

(a)

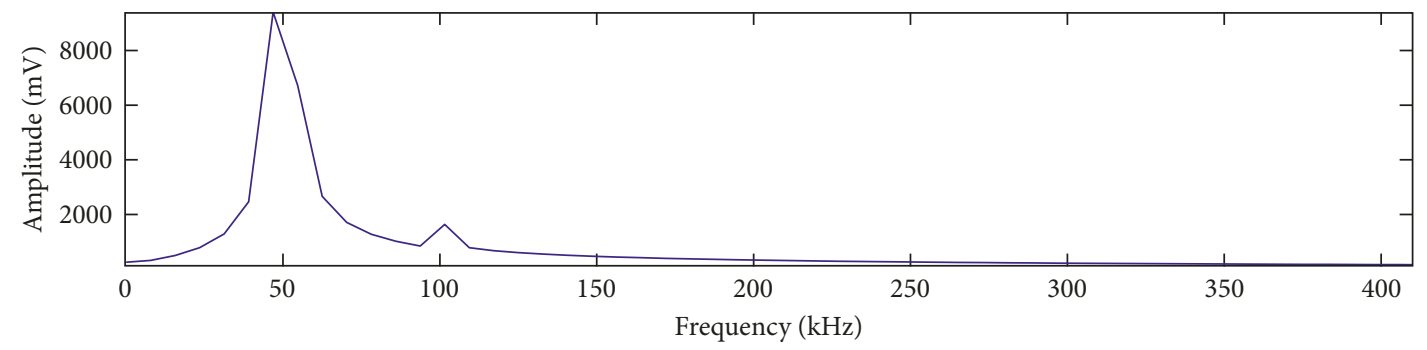

(b)

Figure 2: Time-frequency curve of the numerical signals.

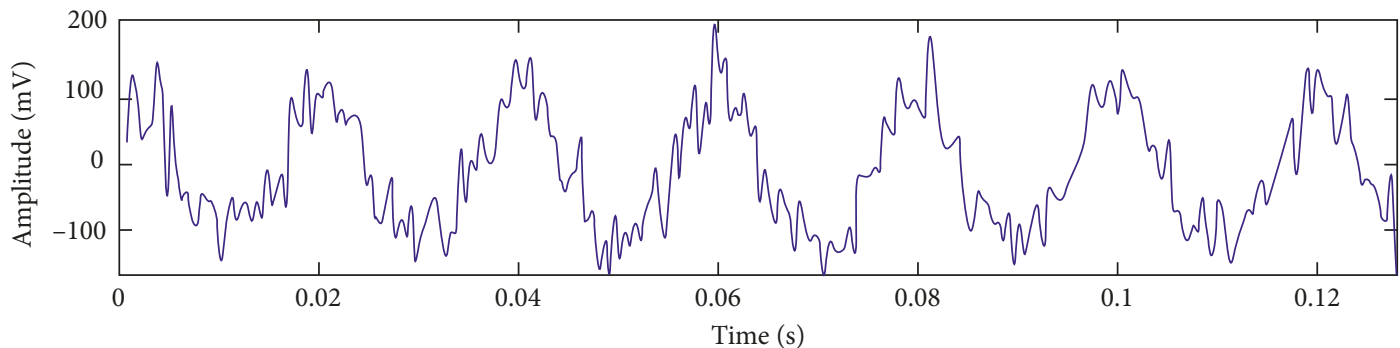

(a)

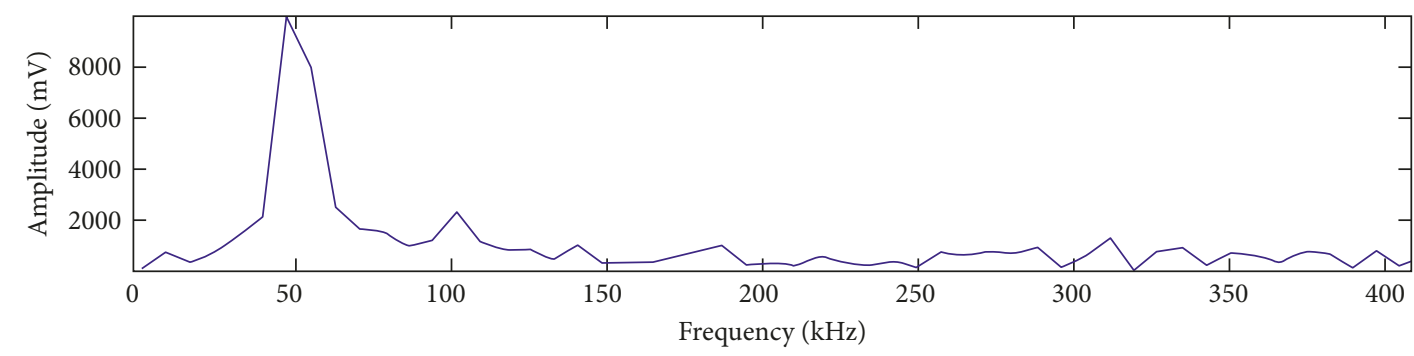

(b)

FIgURE 3: Time-frequency curve of the numerical signal after adding noise.

TABLE 1: Characteristic indicators of the numerical signals after adding noise.

\begin{tabular}{|c|c|c|c|c|c|c|}
\hline SNR & RMSE & $\begin{array}{c}\text { Amplitude of the } \\
\text { fundamental } A_{1}(\mathrm{mV})\end{array}$ & $\begin{array}{c}\text { Amplitude of the second } \\
\text { harmonic } A_{2}(\mathrm{mV})\end{array}$ & $\begin{array}{c}\text { Relative } \\
\text { error } A_{1}(\%)\end{array}$ & $\begin{array}{c}\text { Relative } \\
\text { error } A_{2}(\%)\end{array}$ & $\begin{array}{c}\text { Relative } \\
\text { error } \beta(\%)\end{array}$ \\
\hline 6.54 & 33.31 & 9293 & 2187 & 1.22 & 33.93 & 37.26 \\
\hline
\end{tabular}

differences between them are small when sequence numbers of the wavelet basis are $4 \sim 7$. The SNR achieves best when using Sym6 wavelet base. In summary, we selected the Sym6 wavelet base and three-layer decomposition in wavelet threshold denoising. The detailed denoising indicators are shown in Table 2.
Figure 5 is the time-frequency domain curve of the denoising signal. Compared with the noise signal, the SNR has been greatly improved after wavelet threshold denoising, and the smoothness has also been significantly improved. However, there are still a few burrs in the signal, which need to be further filtered out. 


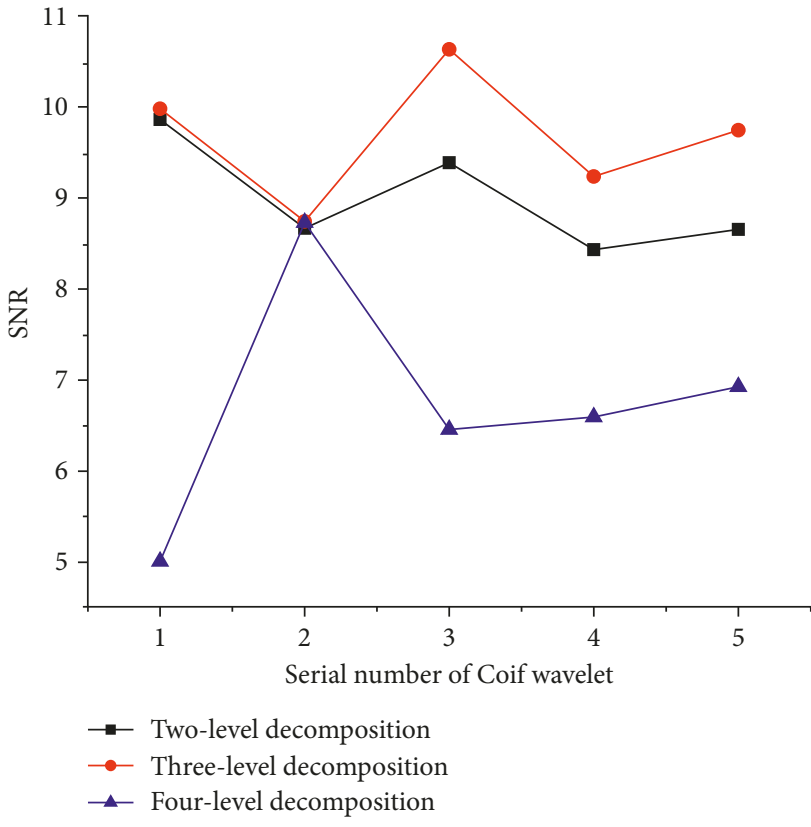

(a)

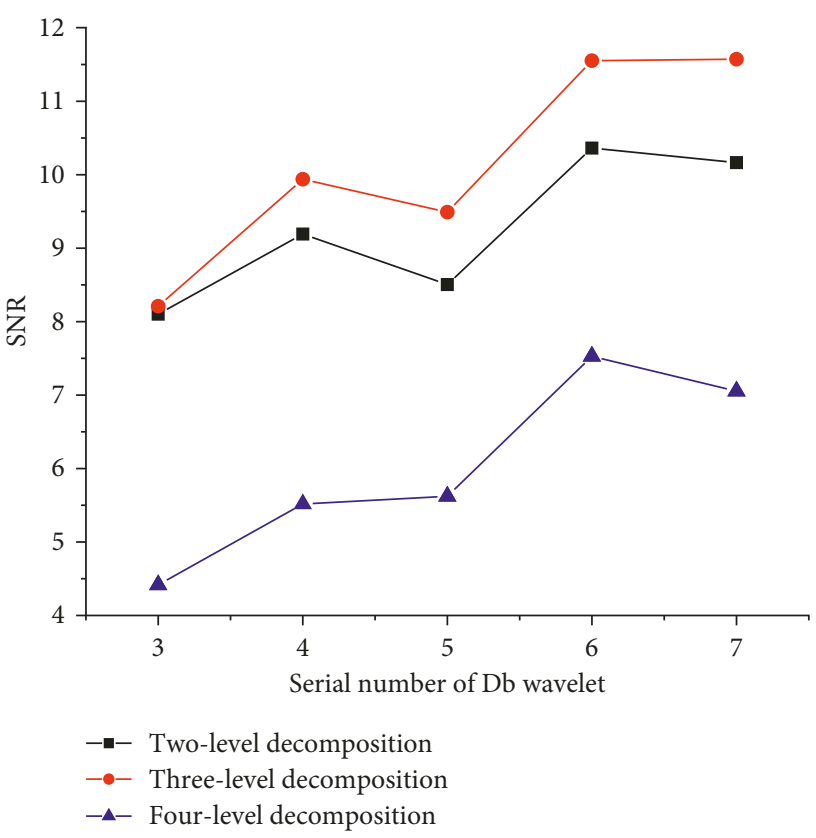

(b)

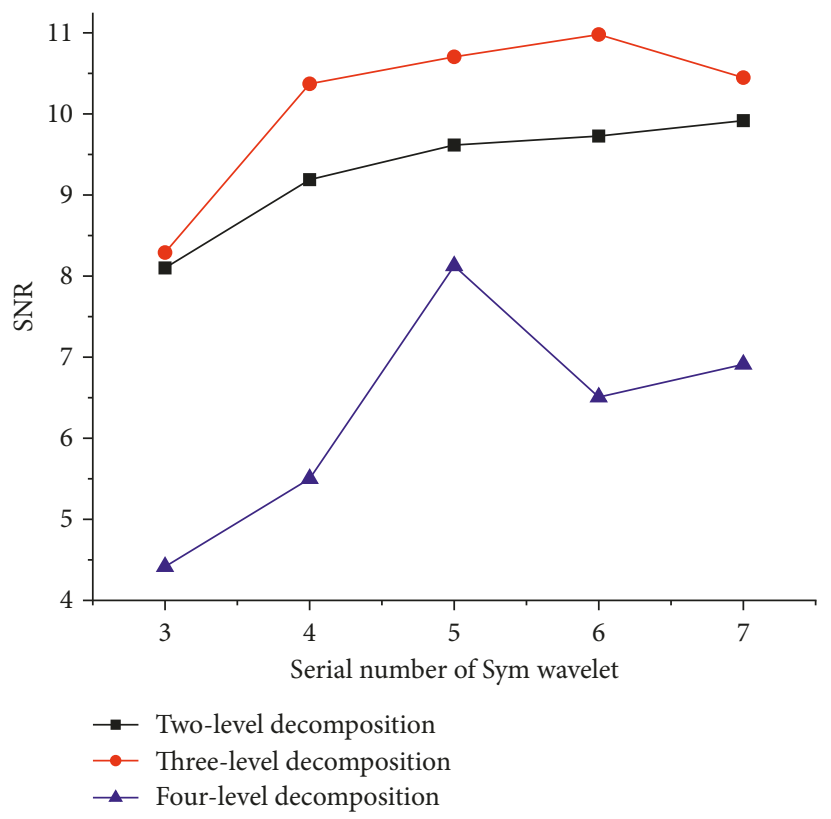

(c)

FIGURE 4: The SNR obtained by denoising with different wavelet bases and decomposition levels. Denoising by (a) Coif wavelet family, (b) $\mathrm{Db}$ wavelet family, and (c) Sym wavelet family.

TABLE 2: Characteristic indicators of the signal after wavelet threshold denoising.

\begin{tabular}{|c|c|c|c|c|c|c|}
\hline SNR & RMSE & $\begin{array}{c}\text { Amplitude of the } \\
\text { fundamental } A_{1}(\mathrm{mV})\end{array}$ & $\begin{array}{l}\text { Amplitude of the second } \\
\text { harmonic } A_{2}(\mathrm{mV})\end{array}$ & $\begin{array}{c}\text { Relative } \\
\text { error } A_{1}(\%)\end{array}$ & $\begin{array}{c}\text { Relative } \\
\text { error } A_{2}(\%)\end{array}$ & $\begin{array}{c}\text { Relative } \\
\text { error } \beta(\%)\end{array}$ \\
\hline 10.98 & 20.00 & 9288 & 1800 & 1.28 & 10.23 & 13.09 \\
\hline
\end{tabular}

3.3. Wavelet and EEMD Joint Denoising. By the method of EEMD, IMF components are obtained (Figure 6). Then, the first two order high-frequency IMF components are discarded and the remaining components are reconstructed. After denoising, the time-domain curve is pretty smooth and no burr can be observed. In this way, the desired denoising effect is achieved.

Comparing the data in Tables $1-3$, it can be seen that the effect of the wavelet threshold denoising is limited and the calculated SNR is hardly ideal. Actually, a large part of the 


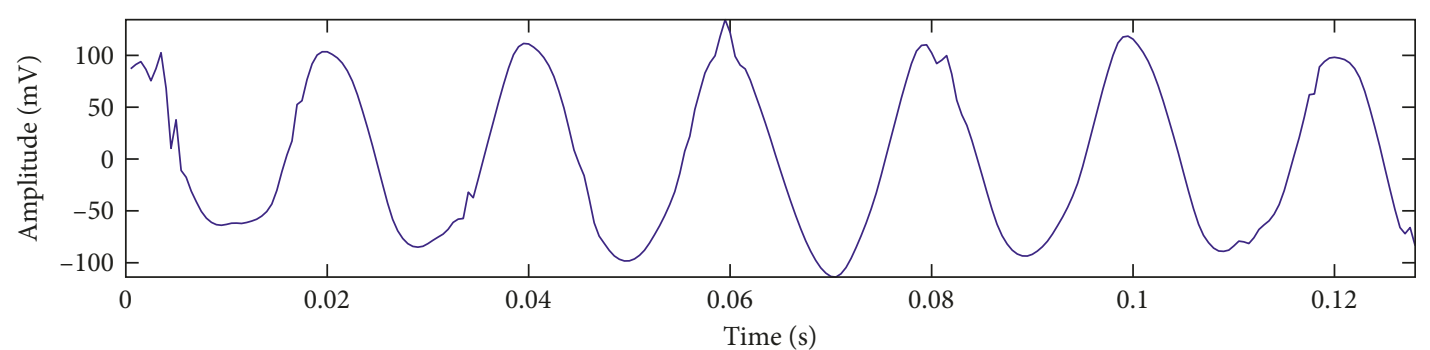

(a)

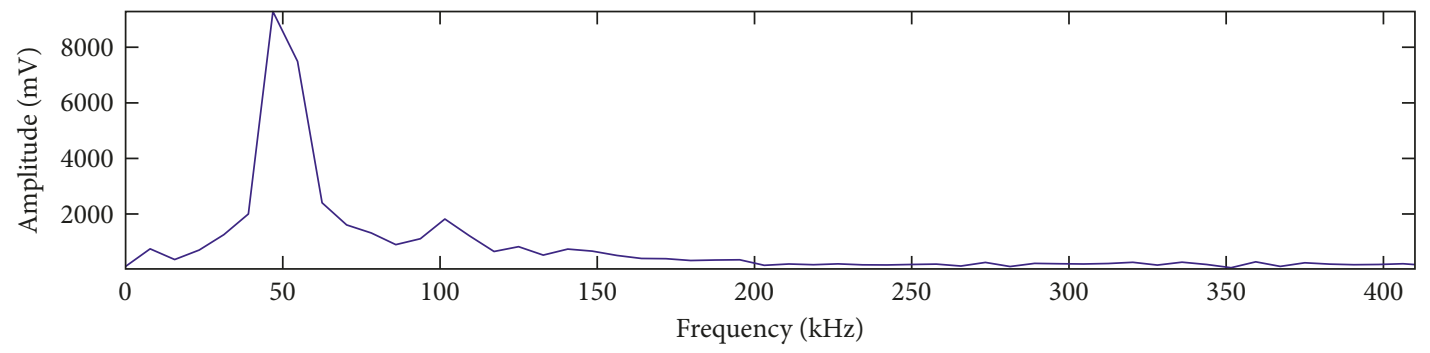

(b)

FIgURE 5: Time-frequency curve after wavelet threshold denoising.
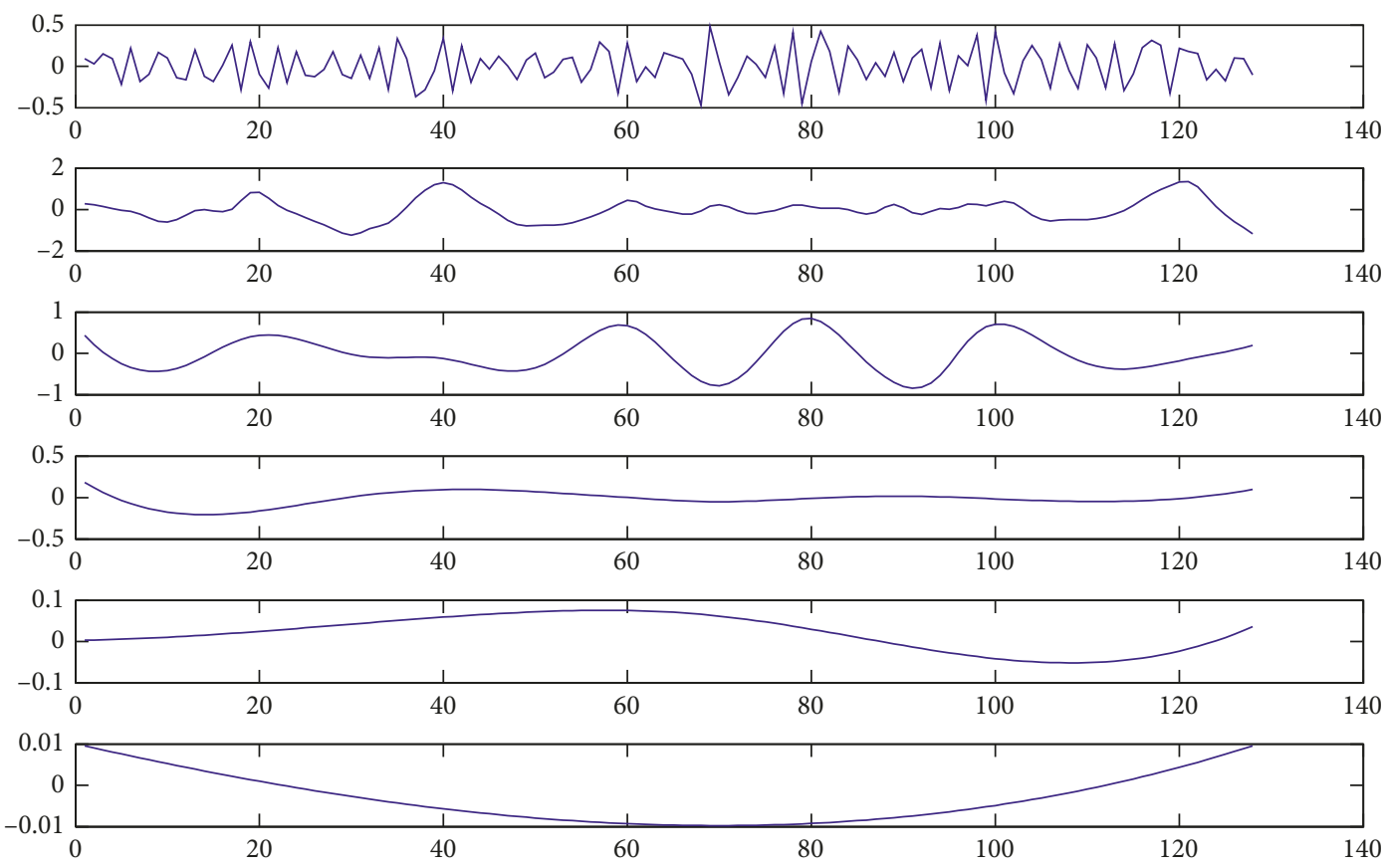

FIgURE 6: IMF components.

nonlinear ultrasonic parameter $\beta$ is caused by noise so that the test accuracy cannot be guaranteed. The proposed method in this paper can greatly improve the accuracy of fundamental and the second harmonic. Furthermore, the error of the nonlinear parameter $\beta$ is reduced dramatically.

It can be seen from Tables $1-3$ that the relative error of the nonlinear coefficient $\beta$ reaches $37.26 \%$ after the Gaussian white noise added. The relative error of the nonlinear coefficient $\beta$ decreases to $13.09 \%$ after the wavelet denoising method. After that, applying the EEMD denoising method to the wavelet denoising signal, the relative error of the nonlinear coefficient decreased to $7.32 \%$.

Compared to the single wavelet denoising method, the relative error of the nonlinear coefficient $\beta$ reduced $5.77 \%$ after using the joint denoising method. Furthermore, by observing Figures 5 and 7, we can conclude that the signal after wavelet denoising still has obvious noise. However, after the EEMD denoising, the time-domain curve of the signal is much smoother. Comparing the changes of the SNR, RMSE, and other indicators, it is confirmed that the denoising 
TABLE 3: Characteristic indicators of the signal after wavelet and EEMD joint denoising.

\begin{tabular}{lcccccc}
\hline SNR & RMSE & $\begin{array}{c}\text { Amplitude of the } \\
\text { fundamental } A_{1}(\mathrm{mV})\end{array}$ & $\begin{array}{c}\text { Amplitude of the second } \\
\text { harmonic } A_{2}(\mathrm{mV})\end{array}$ & $\begin{array}{c}\text { Relative } \\
\text { error } A_{1}(\%)\end{array}$ & $\begin{array}{c}\text { Relative } \\
\text { error } A_{2}(\%)\end{array}$ & $\begin{array}{c}\text { Relative } \\
\text { error } \beta(\%)\end{array}$ \\
\hline 16.89 & 10.12 & 9160 & 1662 & 2.64 & 1.78 & 7.32 \\
\hline
\end{tabular}

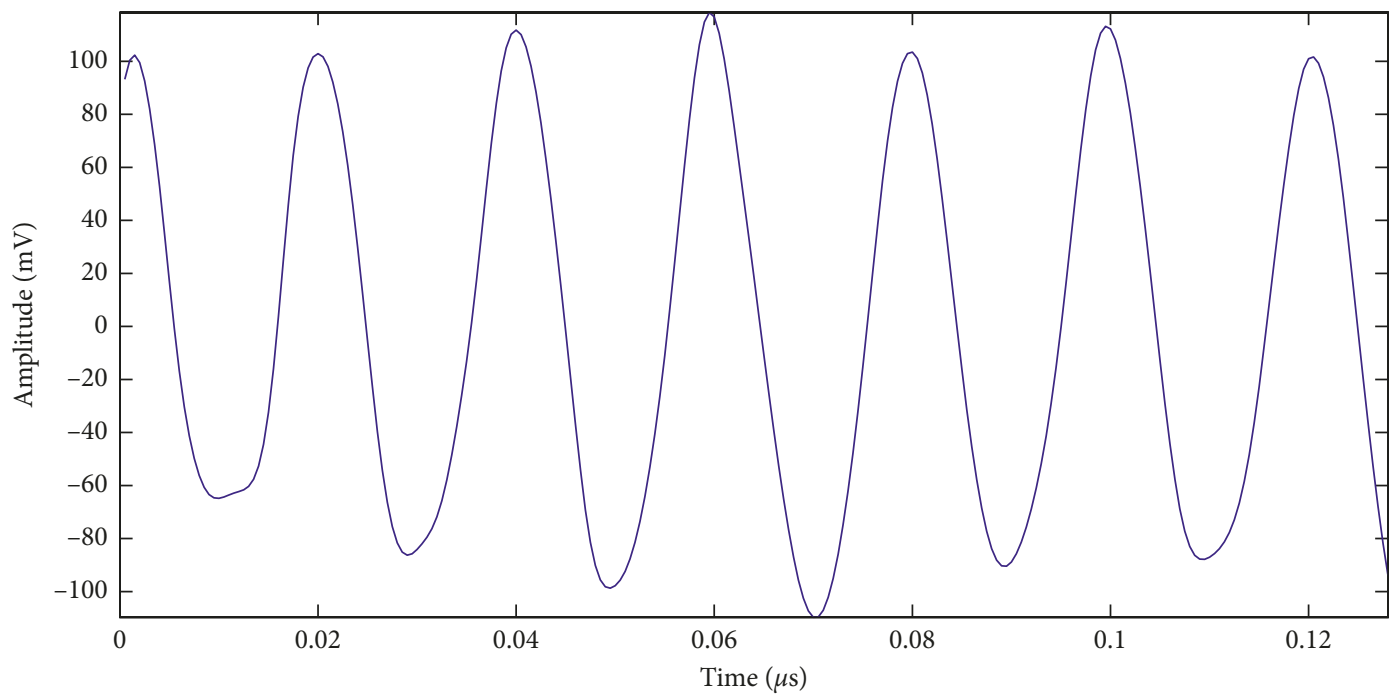

Figure 7: Time-domain curve after wavelet and EEMD joint denoising.

method proposed in this paper is more effective than just using the wavelet denoising method.

\section{Nonlinear Ultrasonic Testing}

4.1. Preparation of Concrete Samples and Test System. In this experiment, microcrack samples and intact samples are prepared for the nonlinear ultrasonic test. The geometric size of the specimen is $20 \mathrm{~cm} * 20 \mathrm{~cm} * 20 \mathrm{~cm}$. The introduction of the microcrack in concrete: Firstly, place the concrete mixture on the vibrating table and vibrate evenly. Then, insert $2 \mathrm{~mm}$ thick steel into the mixture vertically at a certain angle. By clamping the steel sheet out of the samples with a plier after an hour, the low part of the open crack will gradually close due to the geostatic stress and the fluidity of mixture. Eventually, microcracks are formed inside of the concrete (Figure 8). After the concrete completely hardened, the iron wire with a diameter of $0.8 \mathrm{~mm}$ is extended into the crack vertically, and the maximum extension length is $4.5 \mathrm{~cm}$. Thus, we can consider that the formation region of the microcrack in concrete is $10-15 \mathrm{~cm}$ high. The angles of preexisting cracks are $30^{\circ}, 45^{\circ}$, and $90^{\circ}$ (Figure 9).

The nonlinear ultrasonic testing system constructed in this experiment is shown in Figure 10. In this experiment, the GSC-1 engineering ultrasonic imager was used to excite the high-voltage pulse signal and collect the data. The highvoltage electrical pulse signal of one thousand volts is generated by the ultrasonic machine, and the electric signal was converted to the ultrasonic signal by a $50 \mathrm{kHz}$ center frequency compressional wave contact transducer. The ultrasonic signal passed through the concrete specimen and was received by a $100 \mathrm{kHz}$ center frequency transducer. The

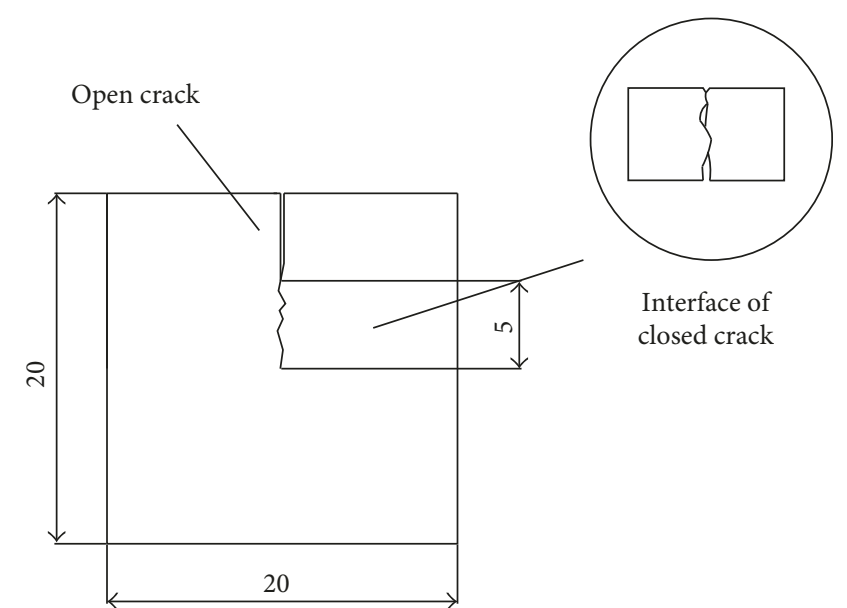

Figure 8: Morphology of the crack (Unit: $\mathrm{cm}$ ).

height of the measuring point is $12 \mathrm{~cm}$. Nonlinear ultrasonic testing was carried out on the same cracked sample at different measuring surfaces, and the nonlinear ultrasonic testing results of five kinds of cracked angles $\left(0^{\circ}, 30^{\circ}, 45^{\circ}, 60^{\circ}\right.$, and $\left.90^{\circ}\right)$ were obtained. In order to minimize the error caused by coupling, Vaseline was evenly coated between the sample surface and transducer and then wound with elastic band tightly. The nonlinear ultrasonic signals were denoised by the wavelet and EEMD joint method.

4.2. Ultrasonic Signal Denoising. Figure 11 shows the timedomain curve of the ultrasonic signal and its details. Comparing with the numerical ultrasonic signal, the test signal is relatively smooth, and the SNR is higher. The reason 


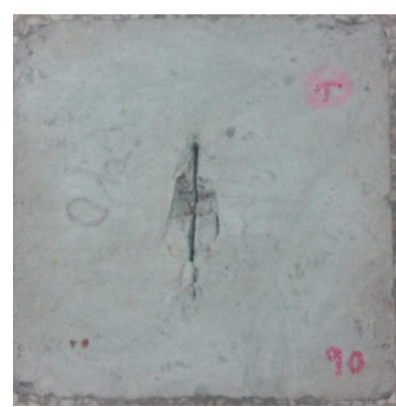

(a)

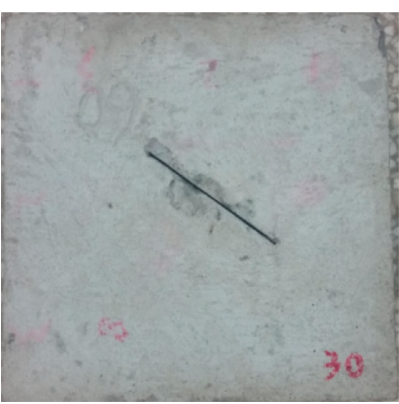

(b)

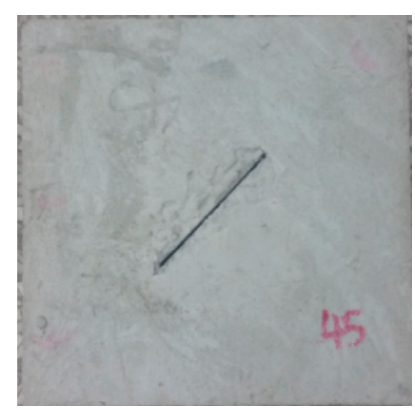

(c)

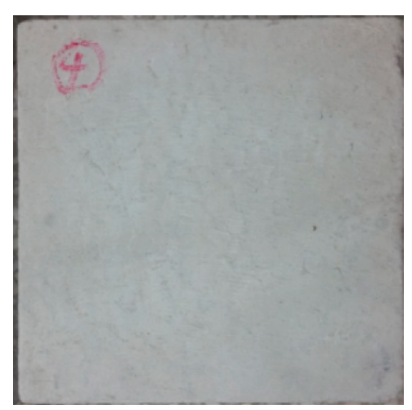

(d)

Figure 9: Cracked and intact samples. Crack: (a) $90^{\circ}$, (b) $30^{\circ}$, (c) $45^{\circ}$, and (d) intact sample.

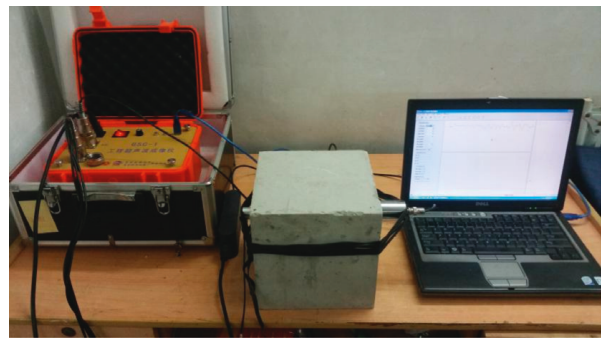

FIGURE 10: The nonlinear ultrasonic testing system.

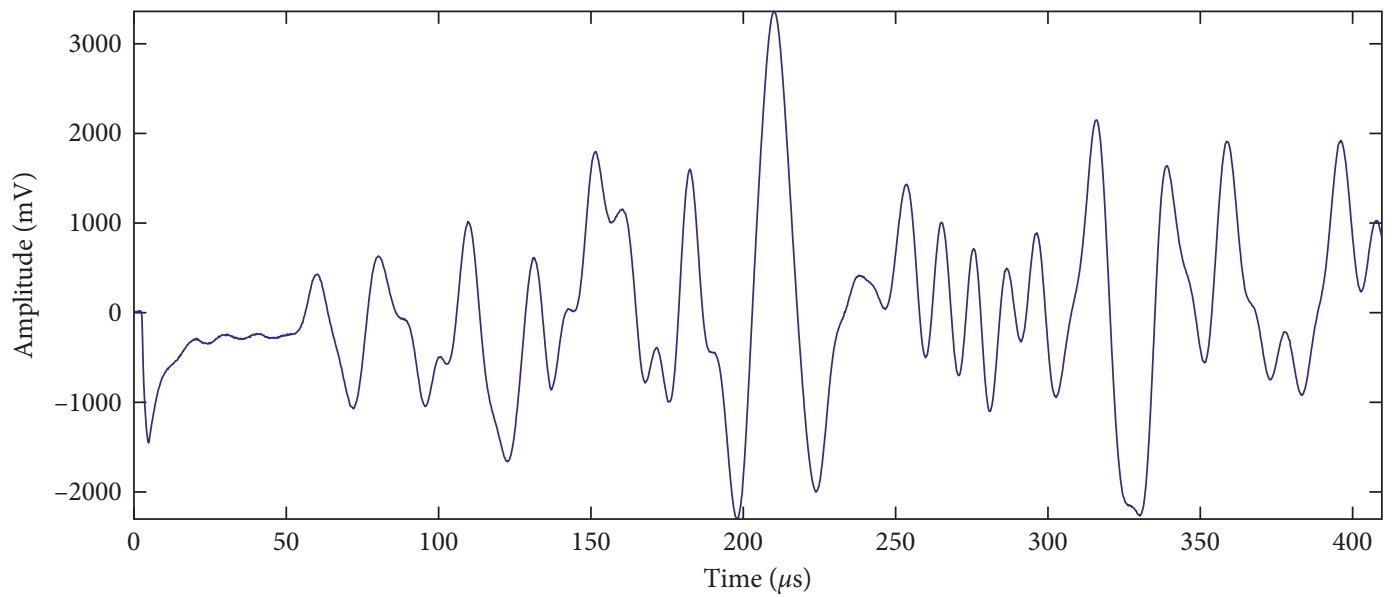

(a)

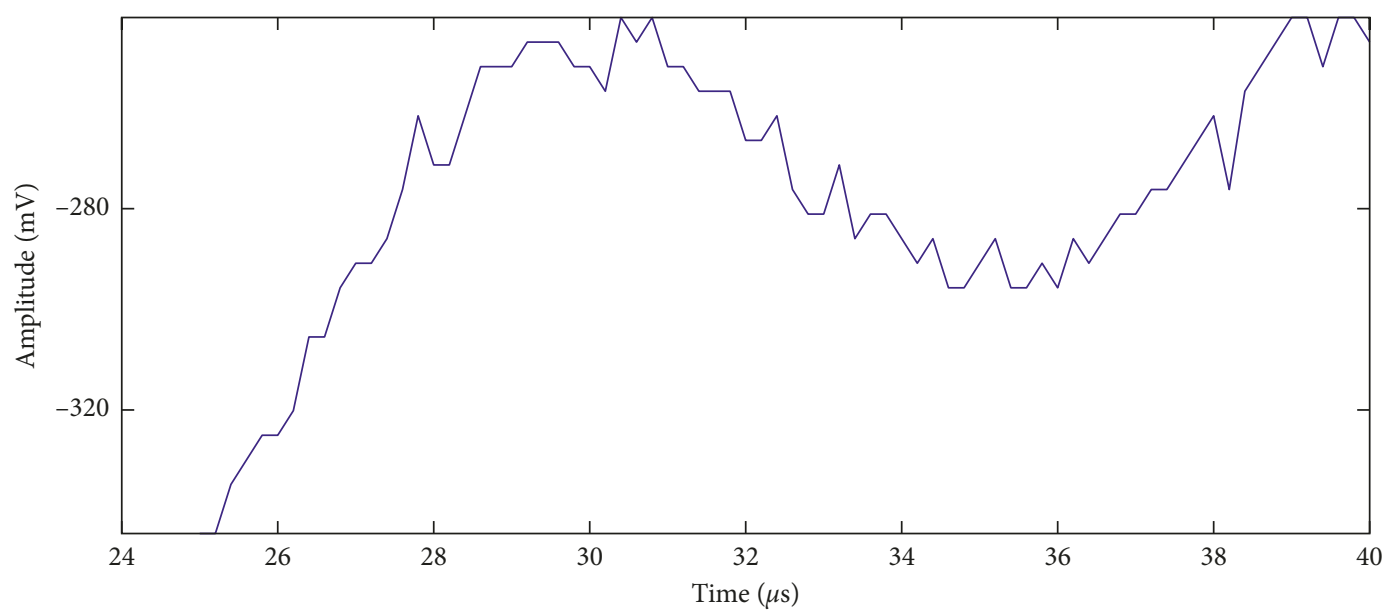

(b)

FIgURE 11: Time-domain curve (a) and minutiae (b) of nonlinear ultrasonic signals. 


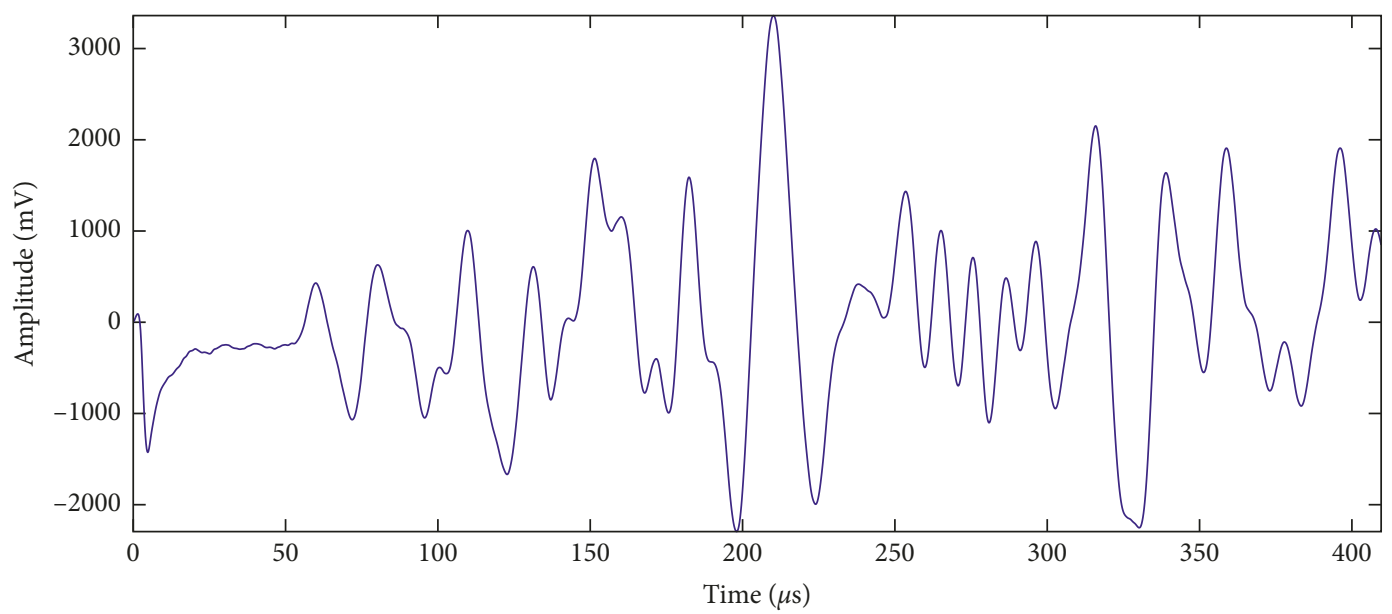

(a)

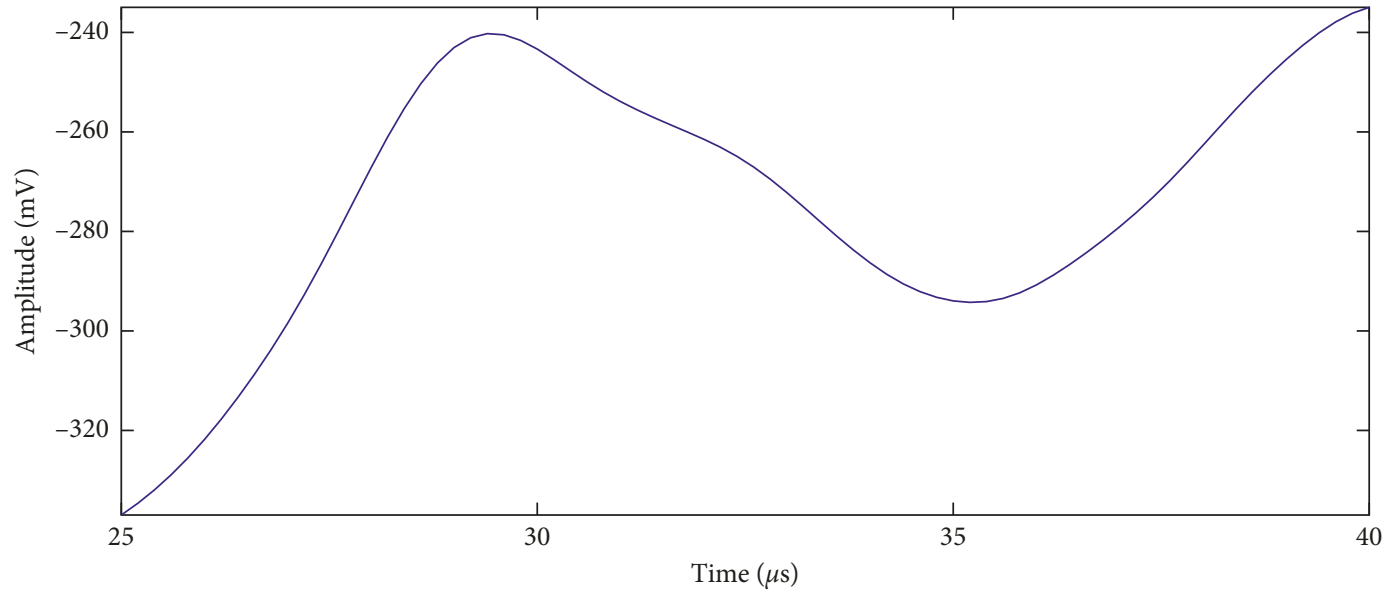

(b)

FIgURE 12: Time-domain curve (a) and minutiae (b) of nonlinear ultrasonic signals after denoising.

for these differences between the two signals is that the test system and environment and the conditions of laboratory ultrasonic testing are more stable. However, a great number of burrs can be observed at a large scale. Because the fluctuation of the noise is tiny and evenly distributed, it can be speculated that the noise is caused by the ultrasonic instrument, voltage, and other system errors. The wavelet and EEMD joint denoising method is used to denoise the nonlinear ultrasonic signal, and the result is shown in Figure 12. It can be seen from Figure 12(b) that the improvement of the minutiae of the signal is obvious, and the burrs are completely removed. The smoothness and SNR of the signal are both better than before.

4.3. Testing Results of Nonlinear Ultrasonic Testing. The nonlinear ultrasonic signal was denoised by the EEMD and wavelet joint method, and the variation law of the parameter $\beta$ and wave velocity $v$ was obtained. The conclusions of the experiment are as follows:

(1) From the height of the two curves in Figure 13, we can conclude that the nonlinear parameter $\beta$ of the cracked samples is larger than that of the intact ones, and the difference between them is obvious. Moreover, it proves that the nonlinear ultrasonic testing has good effect in detecting the microcrack in concrete.

(2) With the increase of the crack angle, the nonlinear parameter $\beta$ we calculated tends to rise as a whole. Notably, the corresponding nonlinear coefficient of the $45^{\circ}$ crack is slightly lower than the previous one and becomes an outlier. The existing linear ultrasonic experiments and numerical simulations show that the wave velocity and the amplitude of the fundamental become smaller due to the strong scattering effect when the angle between the incident wave and crack extension direction increases [22]. Since the nonlinear ultrasonic parameter $\beta$ increases with the crack angle, it can be inferred that the discontinuous forced vibration between the cracks is stronger when the incident wave approaches the vertical direction into the crack contact interface, causing more intense "clapping" effect.

(3) By comparing the wave velocity between intact and cracked samples (Figure 14), it is obvious that the 


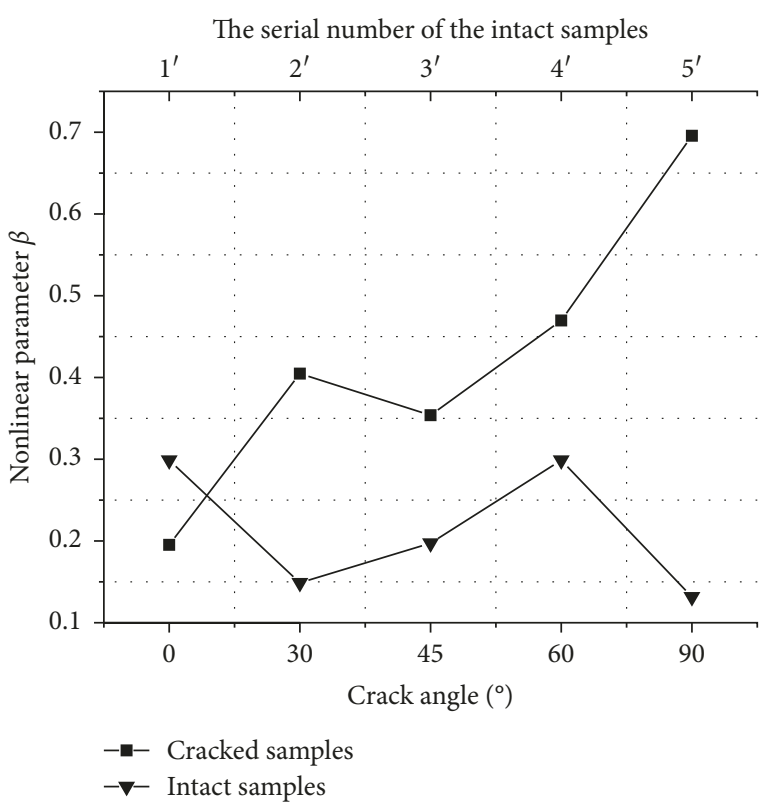

Figure 13: Comparison of the nonlinear parameter $\beta$ between intact and cracked samples.

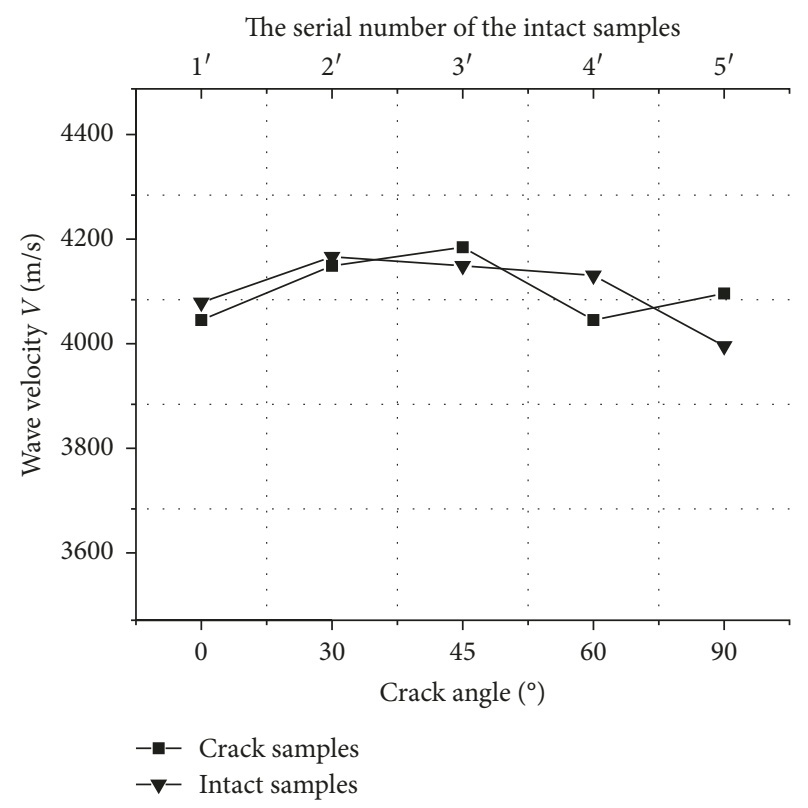

Figure 14: Comparison of wave velocity between intact and cracked samples.

traditional wave velocity is not sensitive to the microcrack in concrete. The maximum change rate is only $2.02 \%$.

\section{Conclusions}

In this paper, the wavelet and EEMD joint denoising method is used to process the nonlinear ultrasonic signal. In this way, the numerical signal is denoised, and the relative error of the nonlinear ultrasonic coefficient $\beta$ decreased from $37.26 \%$ to $7.32 \%$. In addition, the denoising method is carried out on the nonlinear ultrasonic testing data. The main conclusions are as follows:

(1) The denoising results of the numerical and testing data show that the method of wavelet and EEMD joint denoising has good effect on the details of signal. In the actual project, the source of noise (electronic components, environment, etc.) is more extensive, and the SNR will be much lower. Therefore, this method has great potential in engineering applications.

(2) The nonlinear parameter $\beta$ is very sensitive to the microcrack in concrete. The larger the angle between the incident wave and the crack, the larger the nonlinear parameter $\beta$ can be measured. Comparing with the linear ultrasonic parameters $v$ to the nonlinear parameter $\beta$, we can infer that the latter is more sensitive and accurate to characterize the initial damage in concrete.

(3) In this experiment, the ultrasonic signals are denoised to eliminate the part of nonlinear interference caused by regular error and accidental error. However, except the microcrack, there are still many other sources of nonlinear effects, such as coupling agent, ultrasonic instrument, and macrocrack. The experimental study and theoretical analysis on other main nonlinear sources are positive to construct a complete nonlinear ultrasonic evaluation system for concrete materials.

\section{Conflicts of Interest}

The authors declare that they have no conflicts of interest.

\section{Acknowledgments}

This research was funded by the National Natural Science Foundation of China (Grant no. 51609027), and the Chongqing Research Program of Basic Research and Frontier Technology (Grant no. cstc2016jcyjA0016), and the Science and Technology Projects of Chongqing Municipal Education Commission (Grant no. KJ1500527), and the Chongqing Innovative research program for graduates (Grant no. CYB16110). The tests are supported by the Key Laboratory of Water Conservancy and Water Transportation of the Ministry of Education, Chongqing Jiaotong University. The authors appreciate all the institutions and individuals that have provided support for this paper.

\section{References}

[1] K. Y. Jhang, "Nonlinear ultrasonic techniques for nondestructive assessment of micro damage in material: a review," International Journal of Precision Engineering and Manufacturing, vol. 10, no. 1, pp. 123-135, 2009.

[2] C. J. Lissenden, "Towards a micro-mechanics based understanding of ultrasonic higher harmonic generation," in Proceedings of the SPIE Smart Structures + Nondestructive Evaluation, vol. 9438, no. 4, pp. 94380R1-94380R11, San Diego, CA, USA, March 2015. 
[3] J. F. Zhang, F. Z. Xuan, and Y. X. Xian, "Evaluation of material damage using nonlinear ultrasonic wave," Chinese Science Bulletin, vol. 61, no. 14, pp. 1536-1550, 2016.

[4] I. B. Abbasov, "Study of the second harmonics at the scattering of nonlinearly interacting acoustic waves by an elongated spheroid," International Journal of Acoustics and Vibration, vol. 20, no. 4, pp. 258-264, 2015.

[5] O. Giannini, P. Casini, and F. Vestroni, "Nonlinear harmonic identification of breathing cracks in beams," Computers and Structures, vol. 129, no. 4, pp. 166-177, 2013.

[6] G. Kim, J. Y. Kim, K. E. Kurtis, and L. J. Jacobs, "Drying shrinkage in concrete assessed by nonlinear ultrasound," Cement and Concrete Research, vol. 92, pp. 16-20, 2017.

[7] P. Antonaci, C. Bruno, and P. Bocca, "Nonlinear ultrasonic evaluation of load effects on discontinuities in concrete," Cement and Concrete Research, vol. 40, no. 2, pp. 340-346, 2010.

[8] A. A. Shah, Y. Ribakov, and C. Zhang, "Efficiency and sensitivity of linear and non-linear ultrasonics to identifying micro and macro-scale defects in concrete," Materials and Design, vol. 50, no. 17, pp. 905-916, 2013.

[9] S. Biwa, S. Nakajima, and N. Ohno, "On the acoustic nonlinearity of solid-solid contact with pressure-dependent interface stiffness," Journal of Applied Mechanics, vol. 71, no. 4, pp. 508-515, 2004.

[10] A. Romer, J. Y. Kim, J. Qu, and L. J. Jacobs, "The second harmonic generation in reflection mode: an analytical, numerical and experimental study," Journal of Nondestructive Evaluation, vol. 35, no. 1, pp. 1-10, 2016.

[11] W. J. Staszewski, "Wavelet based compression and feature selection for vibration analysis," Journal of Sound and Vibration, vol. 211, no. 5, pp. 735-760, 1998.

[12] W. J. Staszewski, S. G. Pierce, K. Worden, W. R. Philp, G. R. Tomlinson, and B. Culshaw, "Wavelet signal processing for enhanced Lamb-wave defect detection in composite plates using optical fiber detection," Optical Engineering, vol. 36, no. 7, pp. 1877-1888, 1997.

[13] H. H. Hou and Z. G. Gui, "Denosing processing of ECG signal based on wavelet entropy," Chinese Journal of Biomedical Engineering, vol. 29, no. 1, pp. 22-28, 2010.

[14] C. Cunha, A. T. Carvalho, M. R. Petraglia, and A. Lima, "A new wavelet selection method for partial discharge denoising," Electric Power Systems Research, vol. 125, pp. 184-195, 2015.

[15] Z. H. Wu and N. E. Huang, "Ensemble empirical mode decmposition: a noise-assisted data analysis method," Advances in Adaptive Data Analysis, vol. 1, no. 1, pp. 1-41, 2009.

[16] M. Žvokelj, S. Zupan, and I. Prebil, "EEMD-based multiscale ICA method for slewing bearing fault detection and diagnosis," Journal of Sound and Vibration, vol. 370, pp. 394423, 2016.

[17] S. D. Ridder, X. Neyt, N. Pattyn, and P. F. Migeotte, "Comparison between EEMD, wavelet and FIR denoising: influence on event detection in impedance cardiography," in Proceedings of the International Conference of the IEEE Engineering in Medicine and Biology Society, pp. 806-809, Boston, MA, USA, August 2011.

[18] X. Wei, R. Lin, S. Liu, and C. Zhang, "Improved EEMD denoising method based on singular value decomposition for the chaotic signal," Shock and Vibration, vol. 2016, Article ID 7641027, 14 pages, 2016.

[19] D. L. Donoho, "De-noising by soft-thresholding," IEEE Transactions on Information Theory, vol. 41, no. 3, pp. 613627, 1995.
[20] B. Sarkar, S. Sen, D. Dey, and A. Basu, "Linearity abstractions in scene perception: evaluating EEMD for maximizing taskrelated information in event related potentials," Procedia Computer Science, vol. 84, pp. 198-207, 2016.

[21] R. P. Shao, J. M. Cao, and Y. L. Li, "Gear fault pattern identification and diagnosis using time-frequency analysis and wavelet threshold de-noising based on EMD," Journal of Vibration and Shock, vol. 31, no. 8, pp. 96-101, 2012.

[22] H. Fang and X. Y. Deng, "The Influences of cracks in compressional wave velocity," Progress in Geophysics, vol. 13, no. 4, pp. 79-83, 1998. 


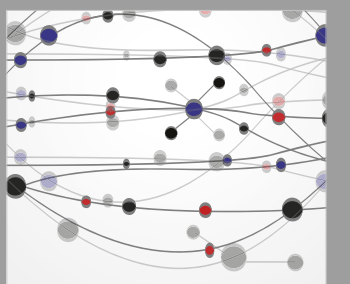

The Scientific World Journal
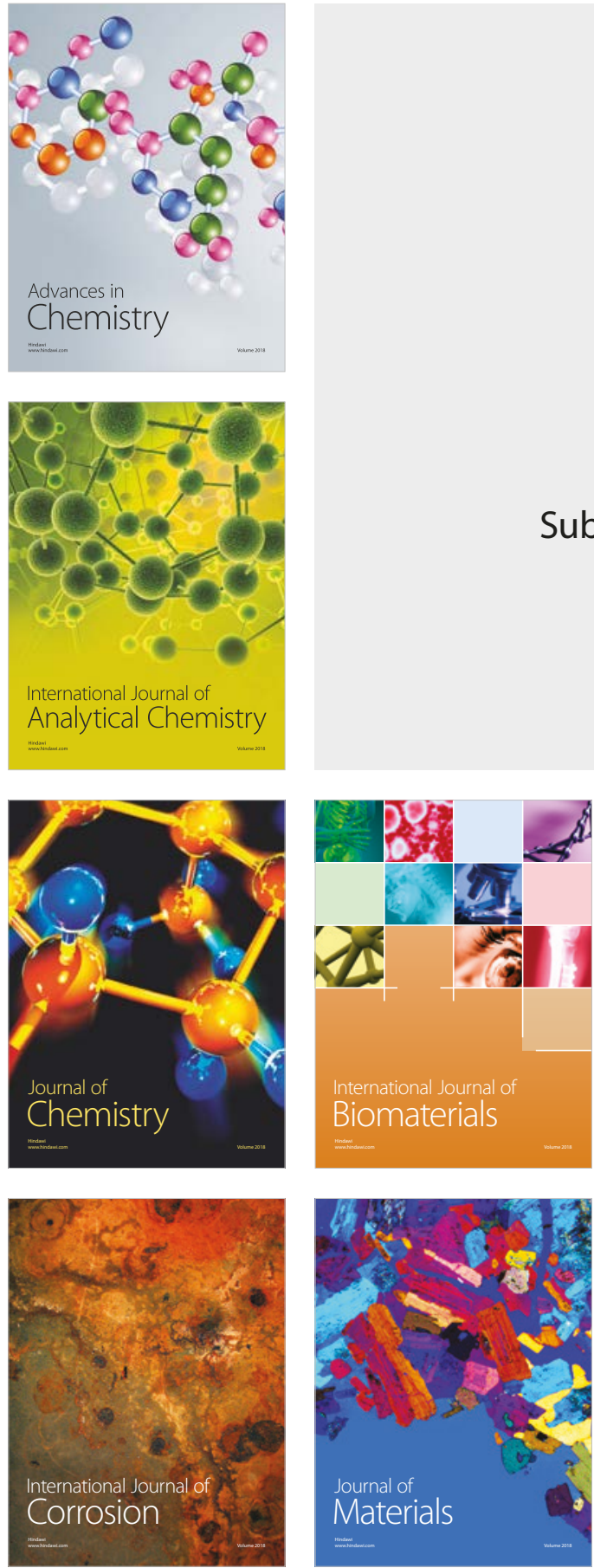

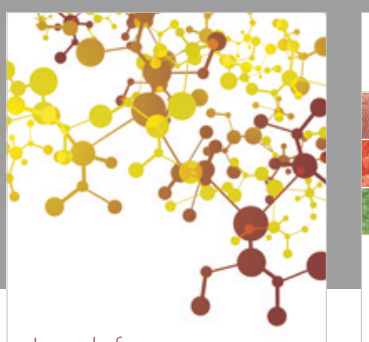

Journal of

Applied Chemistry
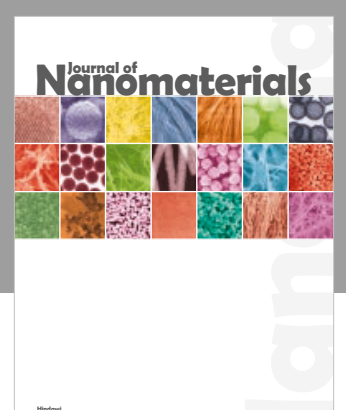

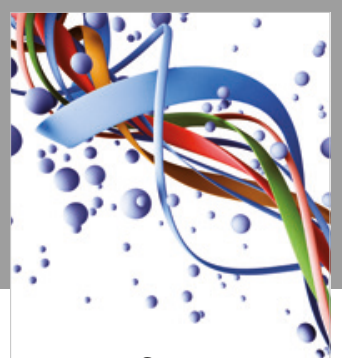

Scientifica

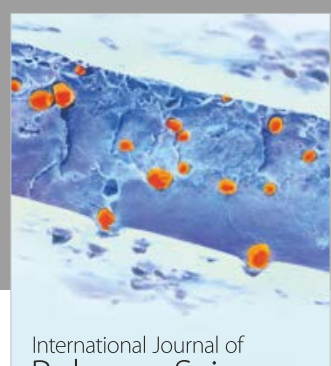

Polymer Science

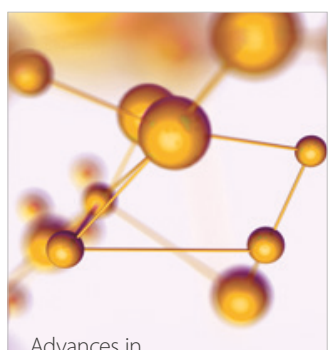

Physical Chemistry
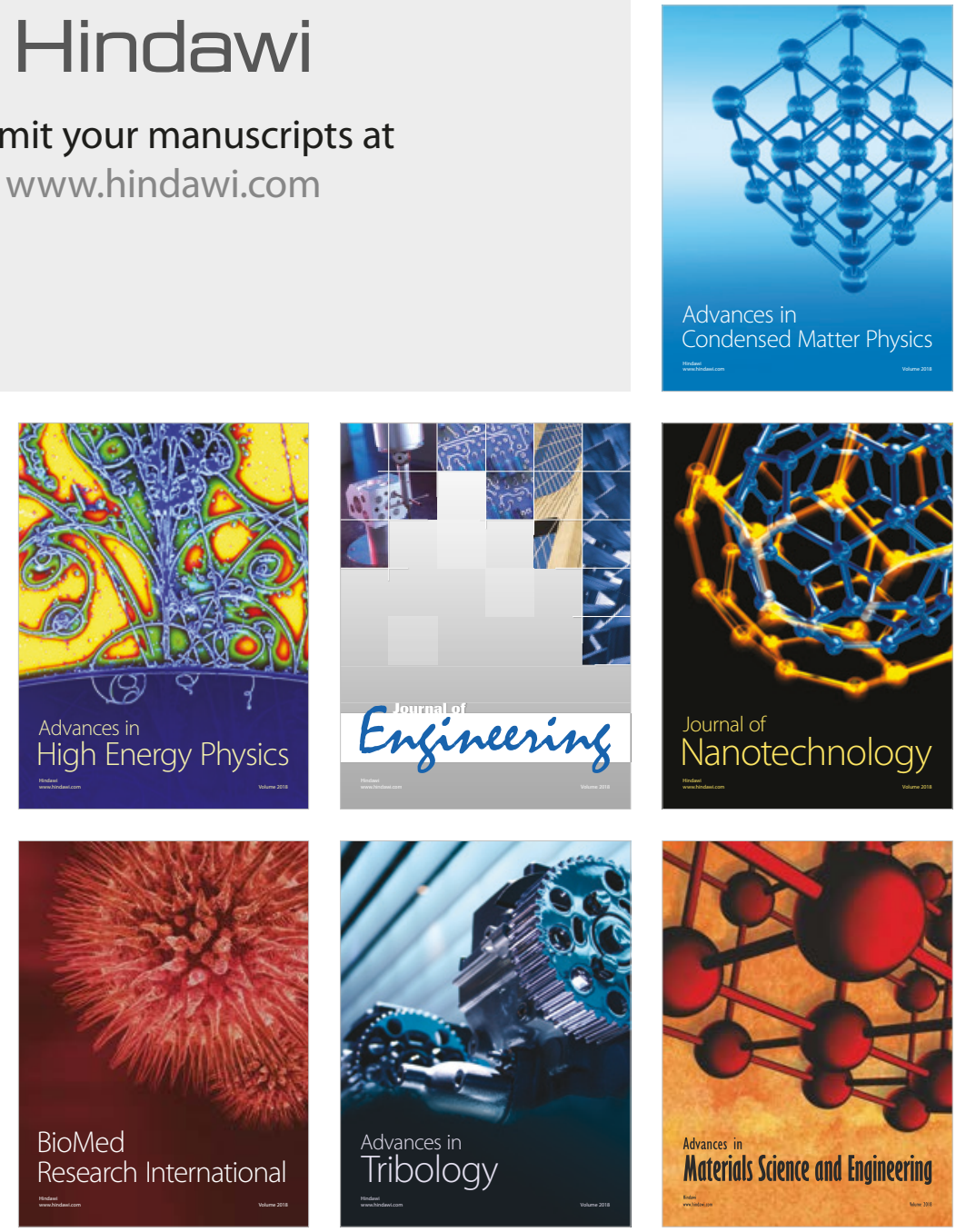